\title{
Efektifitas Permainan Assosiative Terhadap Sibling Rivalry
}

\author{
Firdaus \\ Universitas Nahdlatul Ulama Surabaya, firdaus@ unusa.ac.id \\ Andini Hardiningrum \\ Universitas Nahdlatul Ulama Surabaya
}

\begin{abstract}
Abstrak
Sibling rivalry adalah permusuhan dan kecemburuan antara saudara kandung yang menimbulkan ketegangan diantara mereka. Hal ini terjadi apabila masing-masing anak berusaha lebih unggul dari yang lain. Tujuan penelitian mengetahui efektifitas Permainan Assosiative play terhadap Sibling Rivalry. Populasi penelitian adalah Anak Sibling Rivalry yang bersekolah di PAUD Kasih Ibu Karangrejo VI Wonokromo Surabaya sebesar 32 orang. Besar sampel 30 anak Sibling Revalry, dibagi 2 kelompok yaitu 15 kelompok perlakuan dan 15 kelompok kontrol yang diambil dengan cara probability sampling teknik simple random sampling. Variabel independen Permainan Assosiative play dan variabel dependen Sibling Rivalry. Instrumen pengumpulan data adalah kuesioner sebelum dan sesudah perlakuan permainan Assosiattif Play. Penelitian dilakukan selama 1 bulan yaitu 1 minggu 3 kali perlakuan. Pengolahan data meliputi editing, coding, procesing, cleaning, dan tabulating. Data dianalisa dengan uji Mann-Whitney Test dan uji wilcoxon signed rank test dengan $\alpha<0,05$. Hasil penelitian menunjukkan kelompok perlakuan sesudah permainan Associative play sebagian besar (80\%) mengalami penurunan Sibling Rivalry dengan kategori ringan, sedangkan kelompok kontrol sebagian besar $(53,3 \%)$ mengalami peningkatan Sibling Rival dengan kategori berat. Hasil analisis menggunakan uji Mann-Whitney Test didapatkan nilai $p$ adalah 0.024 dan nilai $\alpha=0.05$, berarti $p>\alpha$ artinya terdapat perbedaan antara Sibling Rivalry pada kelompok kontrol dan kelompok perlakuan, pada uji statistik Wilcoxon sign rank test didapatkan $\rho=0,001<\alpha(0,05)$, artinya terdapat efektifitas permaianan Associative play terhadap Sibling Rivalry di di PAUD Kasih Ibu Karangrejo VI Wonokromo Surabaya. Assosiative Play efektif menurunkan Sibling Rivalry, sehingga disarankan agar orang mampu memperlakukan anaknya dengan baik dan bijak agar sibling bisa teratasi.
\end{abstract}

Kata kunci Assosiative play, Sibling Rivalry

\begin{abstract}
Sibling rivalry is hostility and jealousy between siblings which creates tension between them. This happens if each child tries to be superior to others. The aim of the study was to find out the effectiveness of the associative play game against Sibling Rivalry. The study population was Sibling Rivalry children who attended PAUD Kasih Ibu Karangrejo VI Wonokromo Surabaya for 32 people. The sample size of 30 Sibling Rivalry children was divided into 2 groups, namely 15 treatment groups and 15 control groups taken by means of a probability random sampling technique. Independent variable associative play game and dependent variable Sibling Rivalry. The instrument for collecting data is a questionnaire before and after the treatment of the Assosiattif Play game. The study was conducted for 1 month, namely 1 week 3 times the treatment. Data processing includes editing, coding, processing, cleaning, and tabulating. Data were analyzed by Mann-Whitney test and Wilcoxon signed-rank test with $\alpha<0.05$. The results showed that the treatment group after the Associative play game was mostly $(80 \%)$ experiencing a decrease in Sibling Rivalry in the mild category, while the control group mostly (53.3\%) experienced an increase in Sibling Rival in the heavy category. The results of the analysis using the Mann-Whitney Test obtained $p$-value is 0.024 and the value $\alpha=0.05$, means that $\mathrm{p}>\alpha$ means that there are differences between Sibling Rivalry in the control group and treatment group, in the Wilcoxon sign rank test statistical test $\rho=0.001<\alpha(0,05)$, meaning that the effectiveness of the Associative play game on Sibling Rivalry in PAUD Kasih Ibu Karangrejo VI Wonokromo Surabaya. Associative Play effectively reduces Sibling Rivalry, so
\end{abstract}


it is recommended that people be able to treat their children properly and wisely so that sibling can be overcome

Keywords:Sibling Rivalry, Assosiative play

\section{PENDAHULUAN}

Kata Sibling rivalry masih sangat asing bahkan ada masyarakat yang belum pernah mendengar kata sibling rivalry, namun secara teori sebenarnya masyarakat sudah terjadi sibling rivalry dengan istilah hubungan antara kakak dan adik. Sibling rivalry adalah permusuhan dan kecemburuan antara saudara kandung yang menimbulkan ketegangan diantara mereka. Persaingan dan pertengkaran antara saudara laki-laki dan saudara perempuan, hal ini terjadi pada semua orang tua yang mempunyai dua anak atau lebih (Lusa, 2010).

Sibling rivalry akan semakin besar apabila mereka berjenis kelamin sama dan usia keduanya cukup dekat. Hal ini terjadi apabila masing-masing anak berusaha lebih unggul dari yang lain. Persaingan antara dua saudara kandung dalam memperebutkan kasih sayang dan perhatian orang tua. Konflik yang sering menjadi bahan pertengkaran pada anakanak antara lain berebut mainan, berebut kue, memperebutkan kasih sayang dan perhatian orang tua. Akibatnya apabila tidak tertangani kemungkinan bisa sampai dewasa dan bahkan sampai tua.
Peranan orang tua sangat penting menentukan terjadinya sibling rivalry dalam keluarganya. Salah satunya disebabkan karena anak merasa terancam dengan terbaginya perhatian pada anak yang lain. Menurut Rosydah (2015) anak yang merasa selalu kalah dari saudaranya akan merasa minder atau rendah diri, anak akan menjadi benci terhadap saudara kandung kandungnya sendiri. Seorang kakak yang iri terhadap adiknya menganggap adik sebagai penyebab hilangnya beberapa perhatian yang dimilikinya. Perasaan iri semakin kuat karena adik biasanya lebih diperhatikan, dikasihi dan disayang.

Menurut McNerney dan Joy (dalam Aspuah, 2007) berdasarkan pengalaman yang diungkapkan beberapa orang Amerika dilaporkan $55 \%$ mengalami kompetisi dalam keluarga dan umur 10-15 tahun, serta $45 \%$ anak berumur 2-6 tahun merupakan katagori tertinggi. Penelitian di kabupaten lamongan tepatnya di Babat oleh Nisa (2010) menyatakan bahwa sikap orang tua pada kategori negatif sebanyak 16 orang $(72,2 \%)$ kemudian kategori negatif sebanyak 6 orang tua $(27,3 \%)$. Sibling rivalry tidak terjadi sebanyak 6 anak (72,7\%), terjadi sibling rivalry 
sebanyak 6 anak (27,3\%). Studi pendahuluan yang dilakukan di PAUD Kasih Ibu Karangrejo VI Wonokromo Surabaya didapatkan dari 10 anak mempunyai adik kandung terdapat 7 anak mengalami berebut mainan, 2 anak memukul dan melukai adiknya, dan 1 anak membangkang bila dinasehati. Mereka mengeluh bahwa anak-anak mereka sering memiliki rasa iri hati satu sama lain.

Sibling rivalry pada anak dapat dipengaruhi oleh beberapa faktor antara lain, jarak usia, jenis kelamin, sikap orang tua, jumlah keluarga dan urutan keluarga (Maryunani, 2016). Perbedaan usia umumnya, semakin dekat jarak usia anak dengan saudara kandungnya maka pengaruh diantara mereka semakin besar, terutama dalam kharakteristik emosi. Jenis kelamin, anak laki-laki dan perempuan memiliki reaksi yang sangat berbeda terhadap saudara kandungnya. Anak perempuan dengan saudara perempuan akan terjadi iri hati yang lebih besar dari pada antara anak perempuan dengan saudara kandung laki-laki atau anak lakilaki dengan saudara kandung laki-laki (Nisa dkk, 2010).

Orang tua yang belum mampu untuk bersikap adil akan menimbulkan dampak negatif terhadap hubungan adik dan kakak. Anak akan merasa tidak memiliki harga diri dimata orang tua karena selalu disalahkan ketika bertengkar dengan adiknya, dan kakak akan menyimpan dendam kepada adiknya karena orang tua selalu membela sang adiknya. Apabila benci dan dendam ini sudah tertanam dari kecil maka persaingan yang terjadi pada anak akan membekas dan terbawa sampai dewasa. Bisa jadi seorang kakak menyimpan keinginan untuk membalas dendam kepada adiknya dan akan terjadi regresi pada anak seperti mengompol, manja, anak menjadi nakal. Hal tersebut dilakukan karena ingin mendapatkan perhatian yang lebih dari orang tuanya (Ayu, 2013).

Kejadian sibling rivalry pada anak dapat dicegah yang dapat dipraktekkan oleh orang tua. Orang tua dapat menerapkan bagaimana cara memilih permainan anak yang baik sehingga dapat meminimalisir terjadinya sibling rivalry. Tugas orang dalam permaianan adalah memberikan label pada masing-masing mainan anak agar mereka tidak saling berebut. Selain itu mereka juga akan terdidik untuk menghargai barang milik orang lain serta melatih sikap empati dengan merasakan bila barang miliknya direbut atau dipakai oleh orang lain. Salah satu jenis permainan berdasarkan karakteristik sosial yang dapat diaplikasikan pada anak sibling rivalry adalah 
associative play, pada permainan ini di bimbing agar anak bermain bersama teman-temannya tetapi tidak ada tujuan kelompok. Jika permaianan ini diterapkan maka kemungkinan anak-anak akan memiliki rasa toleransi, berempati satu sama lain serta dapat menyelesaikan masalahnya sendiri tanpa mendatangkan masalah baru

Berdasrakan fenomena diatas, maka peneliti tertarik ingin melakukan upaya pencegahan dan penanganan terhadap Sibling rivalry pada anak di PAUD Kasih Ibu Karangrejo VI Wonokromo Surabaya dengan melakukan bimbingan sosial melalui permainan Assosiative play. Peneliti dapat memberikan edukasi dan melatih orang tua untuk melakukan permainan ini di rumah, sehingga anak Sibling rivalry tertarik dan rutin melakukan permainan assosiative play agar sibling rivalry teratasi.

\section{METODE}

Desain penelitian yang digunakan adalah Quasy-Experiment dengan pendekatan pre post test control group design. Rancangan ini berupaya untuk mengungkapkan hubungan sebab akibat dengan melibatkan kelompok kontrol disamping kelompok eksperimental (Nursalam, 2016). Dalam rancangan ini, kelompok eksperimental diberi perlakuan, sedangkan kelompok kontrol tidak. Pada kedua kelompok diawali dengan pra-test dan setelah pemberian perlakuan pada kelompok eksperimental, dilakukan pengukuran kembali (post-test) pada kedua kelompok. Populasi penelitian adalah Anak Sibling Rivalry yang bersekolah di PAUD Kasih Ibu Karangrejo VI Wonokromo Surabaya sebesar 32 orang, dan besar sampel adalah sebesar 30 responden. Tehnik sampling yang digunakan adalah Simple Random Sampling. Variabel independen dalam penelitian ini adalah Permainan Assosiative play. Instrumen pengumpulan data yang digunakan peneliti adalah lembar kueisoner untuk mengkategorikan sebelum dilakukan perlakuan dan sesudah dilakukan perlakukan Untuk pelaksanaan permainan Assosiative menggunakan permainan balok, mobil-mobilan dan dokter dokteran, disesuaikan dengan umur dan jenis kelamin dan mainan yang disukai anak. Pada kelompok perlakuan permainan dilakukan 1 bulan dalam 1 minggu dan diberikan 3 kali permainan Assosiative play terhadap Sibling Rivalry. Data Sibling Rivalry sebelum dan sesudah pemberian permainan Assosiative play adalah menggunakan uji Mann-Whitney Test, sedangkan untuk mengetahui perbedaan sibling Rivalry Sesudah permainan Associative play Pada Kelompok Perlakuan Dan Kelompok Kontrol Dan uji 
statistika Wilcoxon signed rank test dengan tingkat kemaknaan $\alpha=0,05$. Jika hasil uji statistika menunjukkan $\rho<0,05$ maka hipotesis statistika $\mathrm{H}_{0}$ ditolak dan hipotesis penelitian $\mathrm{H}_{1}$ diterima yang berarti ada pengaruh permainan Assosiative play terhadap Sibling Rivalry

\section{HASIL PENELITIAN}

1. Karakteristik responden berdasarkan Sibling rivalry sebelum di lakukan

Permainan Assosiative play

Tabel 1 Distribusi responden berdasarkan Sibling rivalry sebelum diberi permainan Associative play pada kelompok perlakuan dan kelompok kontrol di PAUD Kasih Ibu Karangrejo VI Wonokromo Surabaya

\begin{tabular}{ccccc}
\hline Sibling & \multicolumn{2}{c}{ Perlakuan } & \multicolumn{2}{c}{ Kontrol } \\
Rivalry & f & $\%$ & f & $\%$ \\
\hline Berat & 9 & 60 & 7 & 46,7 \\
Ringan & 6 & 40 & 8 & 53,3 \\
Jumlah & 15 & 100 & 15 & 100 \\
\hline
\end{tabular}

Pada tabel 1 dapat diketahui bahwa sebelum diberi permainan Associative play pada kelompok perlakuan sebagian besar $(60 \%)$ responden memiliki kategori Sibling Rivalry Berat, sedangkan pada kelompok kontrol sebagian besar $(53,3 \%)$ Memiliki kategori Sibling Rivalry Ringan

2. Karakteristik responden berdasarkan Sibling rivalry sesudah diberi Permainan Assosiative play
Tabel 2 Distribusi responden berdasarkan Sibling rivalry sesudah diberi permainan Associative play pada kelompok perlakuan dan kelompok kontrol di PAUD Kasih Ibu Karangrejo VI Wonokromo Surabaya

\begin{tabular}{lrrrr}
\hline $\begin{array}{l}\text { Sibling } \\
\text { Rivalry }\end{array}$ & \multicolumn{2}{c}{ Perlakuan } & \multicolumn{2}{c}{ Kontrol } \\
\hline Berat & Frek & $\%$ & Frek & $\%$ \\
Ringan & 3 & 20 & 8 & 53,3 \\
Jumlah & 12 & 80 & 7 & 46,7 \\
\hline Pada & 15 & 100 & 15 & 100 \\
Sesudah & 2 & dapat & diketahui & bahwa \\
play pada & kelompok perlakuan sebagian \\
besar (80\%) & responden memiliki kategori \\
Sibling & Rivalry & ringan, sedangkan & pada \\
kelompok kontrol sebagian besar (53,3\%) & Associative \\
berat &
\end{tabular}

3. Perbedaan Sibling Rivalry Sesudah permainan Associative play Pada Kelompok Perlakuan Dan Kelompok Kontrol didapatkan seperti pada tabel berikut:

Tabel 3 Distribusi Frekuensi Perbedaan Sibling Rivalry Sesudah pemberian permainan Associative play di PAUD Kasih Ibu Karangrejo VI Wonokromo Surabaya

\begin{tabular}{cccc}
\hline $\begin{array}{c}\text { Associative } \\
\text { play }\end{array}$ & \multicolumn{2}{c}{ Sibling Rivalry } & \multirow{2}{*}{ Total } \\
\cline { 2 - 3 } & $\begin{array}{c}\text { Berat } \\
\mathrm{f}(\%)\end{array}$ & $\begin{array}{c}\text { Ringan } \\
\mathrm{f}(\%)\end{array}$ \\
\hline Perlakuan & 3 & 12 & 15 \\
& $(20 \%)$ & $(80 \%)$ & $(100 \%)$ \\
Kontrol & 8 & 7 & 15 \\
& $(53,3 \%)$ & $(46,7 \%)$ & $(100 \%)$ \\
\hline
\end{tabular}


Pada tabel 3 menunjukkan bahwa dari 15 responden yang diberi permaianan Associative play sebagian besar (80\%) mengalami penurunan Sibling Rivalry kategori ringan sedangkan dari 15 responden yang tidak permaianan Associative play sebagian besar $(53,3 \%)$ responden mengalami peningkatan Sibling Rivalry yaitu kategori berat.

Berdasarkan uji Mann-Whitney Test didapatkan nilai $p$ adalah 0.024 dan nilai $\alpha=0.05$, berarti $p>\alpha$ maka Ho diterima yang artinya terdapat selisih atau perbedaan antara Sibling Rivalry pada kelompok perlakuan dan kelompok control, sedangkan dari hasil uji statistik Wilcoxon sign rank test di dapatkan nilai $\rho$ adalah 0,001 dan nilai $\alpha=0,05$, berarti $\rho<$ $\alpha$ maka $\mathrm{H}_{0}$ ditolak artinya ada efektifitas terapi permainan Associative play terhadap Sibling Rivalry di di PAUD Kasih Ibu Karangrejo VI Wonokromo Surabaya

\section{PEMBAHASAN}

1. Sibling Rivalry sebelum permainan Associative play

Hasil penelitian pada tabel 1 dapat diketahui bahwa pada kelompok perlakuan sebelum diberi permainan Associative play sebagian besar (60\%) responden memiliki tingkat Sibling Rivalry berat sedangkan kelompok kontrol belum diberi permainan Associative play sebagian besar $(53,3 \%)$ responden memiliki tingkat Sibling Rivalry ringan.

Sibling rivalry adalah perasaan cemburu dan benci yang biasanya dialami oleh anak terhadap kelahiran saudara kandungnya. Perasaan cemburu timbul bukan karena kehadiran saudara barunya melainkan karena adanya perubahan situasi dan kondisi, yang membuat anak cenderung bersifat nakal. Ketika anak terjadi sibling rivalry salah sikap yang ditunjukkan yaitu anak mengalami regresi (mengompol). Menurut pendapat Hurlock (1978) menjelaskan bahwa rasa cemburu merupakan reaksi normal terhadap kehilangan kasih sayang yang nyata, dibayangkan atau ancaman kehilangan kasih sayang. Rasa cemburu timbul dari kemarahan yang menimbulkan sikap jengkel dan ditunjukkan kepada orang lain. Pola rasa cemburu seringkali berasal dari rasa takut yang dikombinasikan dengan rasa marah. Orang yang cemburu merasa tidak tentram dalam hubungannya dengan orang yang dicintai dan takut kehilangan status dalam hubungan kasih sayang itu.

2. Sibling Revalry sesudah dilakukan permaianan Associative play

Setelah dilakukan Permainan Associative play responden mengalami perubahan, terutama pada kelompok perlakuan. 
Permainan Associative play dapat digunakan pada anak Sibling karena jenis permaianan Associative play terjadi komunikasi antara satu anak dengan anak lain, tetapi tidak terorganisasi, tidak ada pemimpin. Merupakan tipe bermain dimana anak bermain dalam kelompok, dengan aktivitas yang sama, dapat saling meminjamkan mainan, tetapi belum teorganisir dengan baik.

Responden pada kelompok kontrol tidak mengalami perubahan penurunan Sibling Rivalry melainkan peningkatan dan cenderung tetap, Orang tua menganggap bahwa jarak kehamilan yang dekat maka akan cenderung menyebabkan pertengkaran pada anak sehingga menyebabkan sibling rivalry. Sedangkan pada kelompok perlakuan yang diberi permainan Associative play responden mengalami penurunan Sibling Rivalry. Permaian Associative play ini dapat berupa bermain peran, bermain menyusun balok, bermain tembak tembakan motor motoran, masak masakan. Dunia anak adalah bermain sambil belajar. Anak diberi kesempatan berinteraksi dengan anggota kelompok, teman sebaya dan hal tersebut terjadi karena adanya kegiatan bermain (Hurlock,1978). Ketika anak bermain bersama teman, anak latihan untuk berbagi. Bermain peran Kadang mengontrol siapa yang boleh bergabung dan siapa yang tidak boleh bergabung dalam kelompok itu.

3. Perbedaan Sibling Revalry sesudah Permainan Associative play pada kelompok perlakuan dan kelompok kontrol di PAUD Kasih Ibu Karangrejo VI Wonokromo Surabaya

Berdasarkan uji Mann-Whitney Test didapatkan nilai $p$ adalah 0.024 dan nilai $\alpha=0.05$, berarti $p>\alpha$ maka Ho diterima yang artinya tidak terdapat selisih atau perbedaan antara Sibling Rivalry pada kelompok perlakuan dan kelompok kontrol. Adanya selisih ini salah satunya karena jenis dan cara pemberiannya jenisnya berupa permainan sesuai dengan umurnya yaitu balok dan lego sedang caranya dengan Cara meminimalkan sibling rivalry dengan bersikap adil, tidak memberikan tuduhan tertentu, membuat anak bekerja sama, memberikan kebebasan, dan tidak membandingkan sedangkan pada kelompok kontrol tidak diberikan tindakan atau bermain sesuka hati anak bermain atau tidak.

4. Efektivitas permainan Associative play terhadap anak Sibling Rivalry di PAUD Kasih Ibu Karangrejo VI Wonokromo Surabaya

Hasil penelitian yang dilakukan dengan menggunakan uji statistik Wilcokson terhadap kelompok perlakuan sebelum dan sesudah pemberian permainan 
menunjukkan efektivitas permainan Associative play terhadap Sibling Rivalry yang terlihat nilai $\alpha=0,05$ didapatkan $\rho=0,001$ dimana $\rho<\alpha$ maka $\mathrm{H}_{0}$ ditolak artinya permainan Associative play efektif terhadap anak Sibling Rivalry di PAUD Kasih Ibu Karangrejo VI Wonokromo Surabaya

Permaianan Associative play adalah permainan yang meningkatkan keterampilan sosial. Keterampilan sosial merupakan salah satu keterampilan yang dapat mempengaruhi kehidupan sosial anak dimasa akan datang. Hubungan antara adik dan kakak yang masih kecil merupakan salah satu interaksi yang berpotensi menimbulkan konflik dan bisa menyebabkan perilaku sibling rivalry terjadi, yaitu permusuhan dan kecemburuanan antar saudara kandung yang dapat menimbulkan ketegangan diantara mereka.

Disimpulkan bahwa permainan Associative play merupakan permainan dapat meningkatkan keterampilan sosial yaitu kemampuan untuk mengadakan komunikasi satu individu dengan individu yang lain sehingga sibling Rivalry bisa teratasi.

\section{REFERENSI}

Aspuah, Siti. 2007. Psikologi Sosial. Jakarta: Rhineka Cipta
Ayu, Sri, dan Rulita. 2013. Dampak Sibling Rivalry (Persaingan Saudara Kandung) Pada Anak Usia Dini. Journal. unnes. ac.id

Azwar, S. 2011. Metode Penelitian. Yogyakarta: Pustaka Pelajar

Chaplin, JP. (2011). Kamus Lengkap Psikologi. Diterjemahkan: Kartini Kartono. Jakarta: PT RadjaGrafindo Persada

Hakuna, 2008. Cara Mengatasi Persaingan Saudara Kandung. Diakses tanggal 4 Agustus 2018

Hurlock, 2012. Perkembangan Anak Jilid 2. Jakarta: Erlangga

Lusa, 2010. SiblingRivalry. http//lusa,web. id/sibling-rivalry.diakses 15 September 2017.

Melinda, 2011. Art Therapy as an Intervention For Autism. Journal of The American Art Therapy Assosiation. Lake Forest, California

Maryunani, 2016. Managemen Kebidanan Terlengkap. Jakarta: CV. Trans Info Media

Nisa, Zuhrotun, dkk, 2010. Hubungan Sikap Orang Tua Dengan Kejadian Sibling Rivalry Pada Anak Usia Toddler Di Desa Gendong Kulon Babat Lamongan Tahun 2010. Lamongan: Jurnal Diakses tanggal 18 Juli 2018

Novairi, A. \& Bayu, A 2012. Bila KakakAdik Berselisih. Jogjakarta: PT Buku Kita

Nursalam, 2016. Metodologi Penelitian Ilmu Keperawatan. Jakarta: Salemba Medika.

Purnama dan yulia 2014. Dampak sibling Revalry pada usia Dini. Journal. unnes. ac.id

Puspita Sari, Eka dan Dwi Rimadhini,Kurnia. (2014). Asuhan Kebidanan Masa Nifas (Postnatal 
Care). Edisi Cetakan Pertama. Jakarta: CV. Trans Info Media.

Rosyida, Wiwied Nur. 2015. Hubungan Antara Kejadian Sibling Rivalry Dengan Tingkat Temper Tantrum Pada Anak Usai Dini. Surabaya. UNUSA.

Setiawati, I \& Zulkaida, A. 2007. Sibling Rivalry Pada Anak Yang Di Asuh Oleh Single Father. Volume 2. Universitas Gunadarma

Tedja Saputra, M. 2005. Bermain, Mainan dan Permainan Untuk Anak Usia Dini. Jakarta: Gramedia 